\title{
DETERMINATION OF 120MM / 46A PREVENTIVE CARE INTERVALS FOR MINVET BOATS FOR INCREASING THE RELIABILITY OF THE SYSTEM
}

\author{
Sutrisno, Arief Saepullah, Setiawan Bernadi Djoko Kriswanto \\ ${ }^{1}$ Indonesian Naval Technology College, \\ Bumimoro-Morokrembangan, Surabaya 60187, Indonesia
}

\begin{abstract}
Most warships, especially corvette types, have a service life of more than twenty years. Intuitively it can be concluded that the components and equipment that have been installed are in the period of wear from the bathtub curve. This paper presents an alternative method in determining the optimum component maintenance intervals for weapons system equipment on ships that have entered wear (wear out). Optimum maintenance costs are determined by optimizing the component maintenance interval with objective functions to minimize the total cost of increasing reliability. The reliability of the system is achieved by increasing the reliability index of its constituent components. Weibull ++ is used to obtain parameters that are appropriate for each damage distribution, while Excel Solvers are used to calculating optimal maintenance intervals. In this writing, a case study will be carried out on the components of Bofors cannon laying gear TAK 120MM / 46A.
\end{abstract}

Keywords: bathtub curves, wear out, maintenance, reliability.

\section{INTRODUCTION.}

Warships are one of the main weapons system tools that have an important role in supporting the implementation of the Navy's operational duties Given the age of warships that have been more than 25 years but have an important role, the right maintenance program is needed for these warships in order to has a long service life with an adequate level of reliability, especially for the Weapon System which is a combat capability of the warship itself. (Defense, 1998)

Maintenance is an activity that is directed at the goal to ensure the functional continuity of a production system or equipment so that the system can be expected to produce the desired results/conditions. (Jardine, 1973). The main purpose of a maintenance activity is to maintain the state of an equipment as close as possible to the desired situation so that the task carried out by the maintenance part is to plan and schedule work to anticipate the level of damage and prevent the production activity from being cut off by providing minimal costs (Defense, 1980)

The main goals of care are defined as follows:

1. To extend the useful life of the equipment. This is very important especially for developing countries which generally have limited resources and lack of availability of spare parts for replacement.

2. To guarantee the optimum availability of installed equipment in the production or operation process.

3. To ensure operational readiness of all equipment needed for emergency use, such as for example standby units, fire engines, and security equipment.

4. To ensure the safety of facility users.

\section{MATERIALS/METHODOLOGY.}

\subsection{Damage Model}

A failure mode of a component or system in general can be mathematically expressed in equation (1). Figure 1 shows the relationship between $X(t)$ state variables and TTF damage time. 
Where : $X(t)= \begin{cases}1 & \text { if } \text { can function } \\ 0 & \text { if failed }\end{cases}$

$X(t)=$ state variable that represents the failure mode condition at time $t$

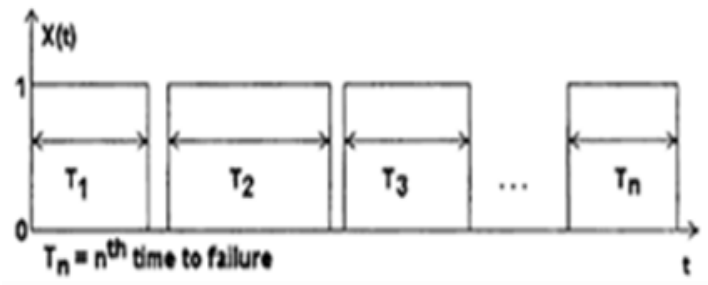

Fig. 1 The relationship between state variable $X(t)$ with TTF damage time

Damage time, TTF, from a failure mode, can follow one of the distributions such as normal, exponential, Weibull, or other distributions. The damage model can be determined by collecting damage data from the analyzed failure mode. Illustration of damage data for a failure mode can also be seen in Figure 1.

\subsubsection{Cumulative Distribution Function (CDF) and Density Function (PDF)}

Assuming that TTF is continuously distributed with the $f(t)$ density function, then the probability of failure mode in the time interval $(0, t)$ can be expressed by the following equation:

$\mathrm{F}(\mathrm{t})=\mathrm{P}(\mathrm{T} \leq \mathrm{t})=\int_{0}^{t} f(\xi) d \zeta$
Where :

$\mathrm{F}(\mathrm{t})=$ cumulative distribution function (CDF) of TTF random variables

The pdf function of the random variable $\mathrm{T}$ can be determined from equation (2) by taking the derivative of $F(t)$ to $t$ as shown in equation (3).

$$
\begin{aligned}
f(\mathrm{t}) & =\frac{d}{d t} F(t)=\lim _{\Delta t \rightarrow 0} \frac{F(t+\Delta t)-F 9 t)}{\Delta t} \\
& =\lim _{\Delta t \rightarrow 0} \frac{P(t<T \leq t+\Delta t)}{\Delta t} \ldots \ldots . .(3)
\end{aligned}
$$

\subsubsection{Reliability Functions}

The reliability function is a function that represents the probability that failure mode (Kececioglo, 2002) does not cause a failure in the time interval $(0, t)$ and is expressed by the following equation:

$R(t)=1-F(t)=P(t>t)$

$=\int_{t}^{\infty} f(\zeta) d \zeta$

Equation (2) can also be called a function of unreliability and is expressed by $Q$ (t).

\subsubsection{Damage Rate}

The conditional probability failure rate is the probability that a damage occurs during a certain time but the damage has not occurred before that time (Han, 2000). Therefore, the damage rate provides additional information about the survival life and is used to illustrate the damage pattern. The probability of a failure mode will cause a failure in the time interval $(t+\Delta t)$, it is known that the failure mode operates at time $t$, it can be determined by the following equation:

$$
\begin{array}{r}
\mathrm{P}(\mathrm{t}<\mathrm{T} \leq \mathrm{t}+\Delta \mathrm{t})=\frac{P(t<T \leq t+\Delta t)}{P(T>t)} \\
=\frac{F(t+\Delta t)-F(t)}{R(t)}
\end{array}
$$

The damage rate, $z(t)$, from a failure mode can be obtained by dividing equation (5) with the length of the time interval $\Delta t$ and $\Delta \mathrm{t} \rightarrow 0$.

$$
\begin{aligned}
& z(t)=\lim _{\Delta t \rightarrow 0} \frac{P(t<T \leq t+\Delta t \mid T>t)}{\Delta t} \\
& =\lim _{\Delta t \rightarrow 0} \frac{F(t+\Delta t)-F(t)}{\Delta t} x \frac{1}{R(t)} \\
& =\frac{f(t)}{R(t)}
\end{aligned}
$$




\subsubsection{Failure Pattern}

Understanding that equipment failure modes can exhibit different damage patterns has important implications in determining the characteristics of a fault. Figure 2 shows the characteristics of the damage (Moubray, 1997).

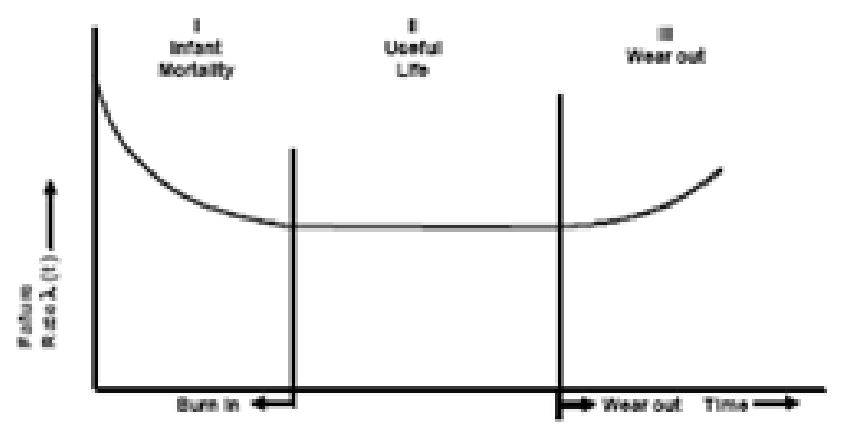

Fig. 2 Damage characteristics

These characteristics are:

- Wear-in Failure, which is dominated by "weak" devices such as manufacturing defects and installation errors. This characteristic is also known as damage to burn in or infant mortality.

- Random Failure, which is dominated by the damage that cannot be predicted or because of a chance/chance (chance failures). This characteristic is characterized by a constant damage rate and the damage distribution shows an exponential distribution.

- Wear-out Failure, which is dominated by the end use of equipment. These characteristics are characterized by increasing rates of damage and distribution of damage showing the Weibull distribution.

To determine the distribution types of damage characteristics, Weibull ++ 4 software was used.

\subsection{Probability Distribution}

Probability distributions can vary to state the distribution that best suits damage data. The probability distributions used to model the failure mode of any functional damage of the diesel motor drive system are normal, exponential, and Weibull distributions.

The normal distribution is chosen based on the assumption of the central limit theorem. The exponential distribution is chosen based on the characteristics that represent the useful life period. While the Weibull distribution is chosen based on the flexibility of the parameters in determining the pattern of damage from existing data that may lie in the period of useful life or period of wear out.

\subsubsection{Exponential Distribution}

If the $T$ damage time of an exponentially distributed failure mode with parameters is $\lambda$ and $y$ then the pdf function of $T$ is determined by:

$f(t)=\lambda e^{-\lambda(t-y)}$

Where:

$\lambda=$ rate of damage

$Y=$ form parameter

The reliability function of the exponential distribution becomes:

$R(t)=e^{-\lambda(t-y)}$

While the function of the exponential distribution damage rate is:

$z(t)=\lambda$

Equation (7) is known as an exponential distribution with two parameters. An exponential distribution with one parameter is obtained if $\mathrm{y}$ is equal to zero.

\subsubsection{Weibull distribution}

Weibull distribution is one of the most widely used distributions in the field of reliability engineering (McCool, 2012). This is because the distribution has the ability to 
model different and many data by setting the parameter value of the form $\beta$. The pdf function of the three parameters of the Weibull distribution is stated by:

$f(t)=\frac{\beta}{\eta}\left(\frac{t-\gamma}{\eta}\right)^{\beta-1} e^{-\left(\frac{t-\gamma}{\eta}\right)^{\beta}}$

Where:

$\beta=$ parameter form, $\beta>0$

$\eta=$ scale parameter, $\eta>0$

$\mathrm{Y}=$ location parameter, $\mathrm{y}<$ first time of damage

The reliability function of the Weibull distribution can be stated by:

$$
R(t)=e^{-\left(\frac{t-\gamma}{\eta}\right)^{\beta}}
$$

And the rate of damage can be stated by:

$$
z(t)=\frac{\beta}{\eta}\left(\frac{t-\gamma}{\eta}\right)^{\beta-1}
$$

If $\mathrm{Y}=0$, we get a Weibull distribution with two parameters.

\subsubsection{Normal Distribution}

Normal distribution (Gaussian) is the distribution most often used in statistics. Random variable $T$ is stated to be normally distributed with mean $\mu$ and variant $\sigma 2, T \sim N$ $(\mu, \sigma 2)$ if the pdf function of $T$ is

$$
f(t)=\frac{1}{\sigma \sqrt{2 \pi}} e^{-\frac{1}{2}\left(\frac{t-\mu}{\sigma}\right)}
$$

Where:

$\sigma=$ standard deviation of random variables $T$ $\mu=$ average of random variables $T$

The reliability function of a normal distribution is:

$$
\begin{aligned}
& R(t)=\int_{t}^{\infty} \frac{1}{\sigma \sqrt{2 \pi}} e^{-\frac{1}{2}\left(\frac{t-\mu}{\sigma}\right)} d t \\
& =1-\Phi\left(\frac{t-\mu}{\sigma}\right)
\end{aligned}
$$

Where:

$\Phi=$ CDF function from normal distribution Damage rate from normal distribution can be obtained using equation (6).

\subsection{Allocation of Reliability and Optimization for Complex Systems}

According to Mettas (Geuna, Weber and Theulliol, 2011), increasing system reliability cannot be achieved only by increasing the reliability of one component. System reliability can be achieved if all component reliability is improved. But the question is the feasibility of the component being enhanced reliability. To answer this question one of the factors to consider is the cost. The next challenge is then a model for cost as a function of reliability.

In the model of component reliability allocation according to the cost to increase reliability, high cost components will get the lowest reliability improvement. But in this study, the author will discuss the function of costs as a penalty cost of increasing component reliability. The minimum system cost as an objective function is the sum of the costs of each component. The formulation of the problem is as follows:

Objective function:

$$
\operatorname{Min} \mathrm{C}=\sum_{i=11}^{n} c_{i}\left(R_{i}\right)
$$

Subject to

$\mathrm{RS} \geq \mathrm{RG}$

$\mathrm{Ri}, \min \leq \mathrm{Ri} \leq \mathrm{Ri}, \max$,

Where:

$\mathrm{C}=$ total system cost

$\mathrm{Ci}(\mathrm{Ri})=$ component cost $/$ sub system $\mathrm{i}$

$\mathrm{Rs}=$ system reliability

$R G=$ expected system reliability

$\mathrm{Ri}, \min =$ Minimum / initial component $/$ sub system reliability $i$ 
$\mathrm{Ri}, \max =$ Maximum / expected reliability of components / sub systems $\mathrm{i}$

$\mathrm{i}=1,2,3, \ldots \ldots . \mathrm{n}$

\subsubsection{Cost function}

The above formulation is designed to achieve a minimum total system cost with a minimum system reliability value limiting function that must be fulfilled. The initial step is to obtain a reliability function analysis, then proceed with determining the cost relationship of each component as a function of reliability. This relationship can be obtained from historical data from similar components. But in some cases, the data is not available. To overcome these problems, (Hartanto, 2016) proposed the following forms of cost functions:

$$
\begin{gathered}
c_{i}\left(R_{i} ; f_{i}, R_{i, \text { min }}, R_{i, \text { max }}\right)= \\
e^{\left[f_{i} \frac{R i-R i, \min }{R i, \max -R i}\right]}
\end{gathered}
$$

Where:

$\mathrm{Ci}(\mathrm{Ri} ; \mathrm{fi}, \mathrm{Ri}, \mathrm{min}, \mathrm{Ri}, \mathrm{mx})=$ component $/$ subsystem costs $i$

$\mathrm{Ri}, \min =$ Minimum (initial) reliability of components / sub-systems i

$\mathrm{Ri}, \max =$ Maximum component $/$ sub system reliability $i$

$\mathrm{i}=1,2,3, \ldots \ldots . \mathrm{n}$

$\mathrm{fi}=$ feasibility (feasibility) of components / sub-systems to be improved

\section{RESULT AND DISCUSSION}

\subsection{Optimization Model Making}

The programming model to get the optimal values of each component of the Laying Gear can be described as follows:

\section{A. Inputs}

> Komponen Component Damage Data (TTF).
> Distribusi Distribution parameters (Weibull 3 parameters); $\beta, \eta, y$

$>$ Feasibility component.

\section{B. Equations}

$>$ Component costs:

$c_{i}\left(R_{i}\right)=e^{\left[f_{i} \frac{R_{i}-R_{i, \min }}{R_{i, \max }-R_{i}}\right]}$

Where,

$\mathrm{C}_{\mathrm{i}}\left(\mathrm{R}_{\mathrm{i}}\right)=$ component cost

$R_{i}=$ value of component reliability $i$

$\mathrm{R}_{\mathrm{i}, \text { min }}=$ component's initial reliability index $\mathrm{i}$

$\mathrm{R}_{\mathrm{i}, \max }=$ expected component reliability index $\mathrm{i}$

$f_{i}=$ component feasibility to be improved reliability.

\section{Constraints}

> Sistem System Reliability Value $\left(\mathrm{R}_{\mathrm{s}} ;\right) ; 0.92$ $\leq R_{\mathrm{s}} \leq 0.999$

> Component drag value $\left(\mathrm{R}_{\mathrm{i}}\right) ; \mathrm{R}_{\text {awal }} \leq \mathrm{R}_{\mathrm{i}} \leq$ 0.999

D. Output (Decision Variable)

Component maintenance time interval

\section{E. Objective Function}

Minimize the cost of increasing system reliability:

$C=\sum_{1}^{n} c_{i}\left(R_{i}\right)$

Where,

$\mathrm{C}=$ Total system costs

$\mathrm{C}_{\mathrm{i}} \mathrm{R}_{\mathrm{i}} \quad=$ cost of increasing component reliability

$\mathrm{n}=$ number of components

$i=1,2,3, \ldots \ldots \ldots . . . n$

Figure 3 shows the flow diagram of reliability optimization calculations, while Figure 4 shows the optimization modeling structure of the components of laying gear. 


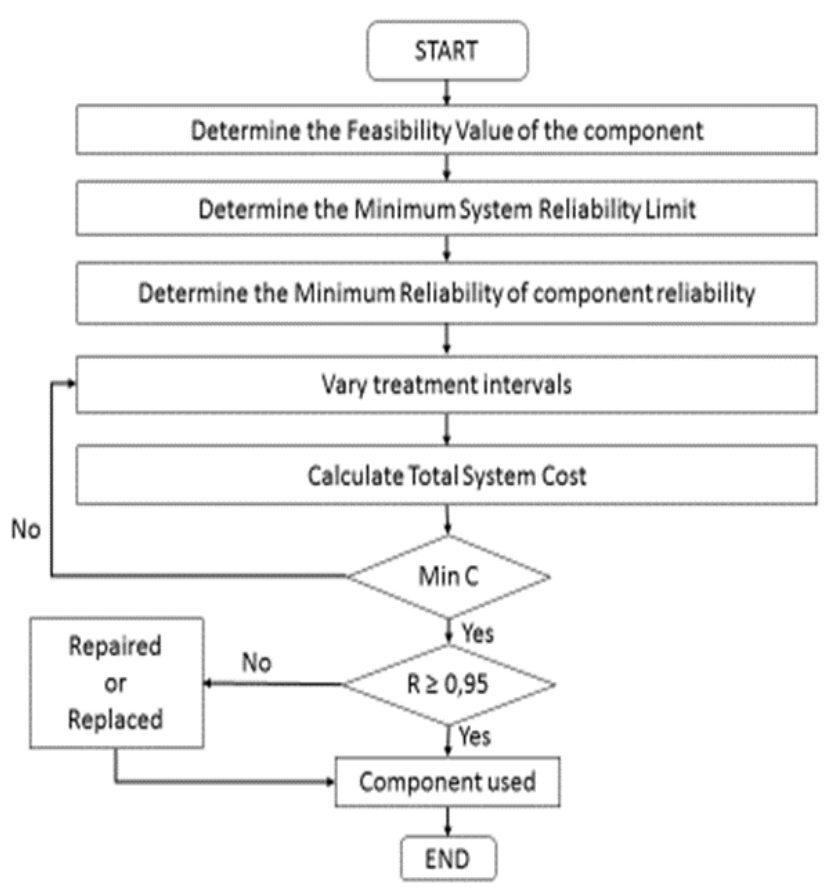

Fig. 3 Flow chart of the optimization process

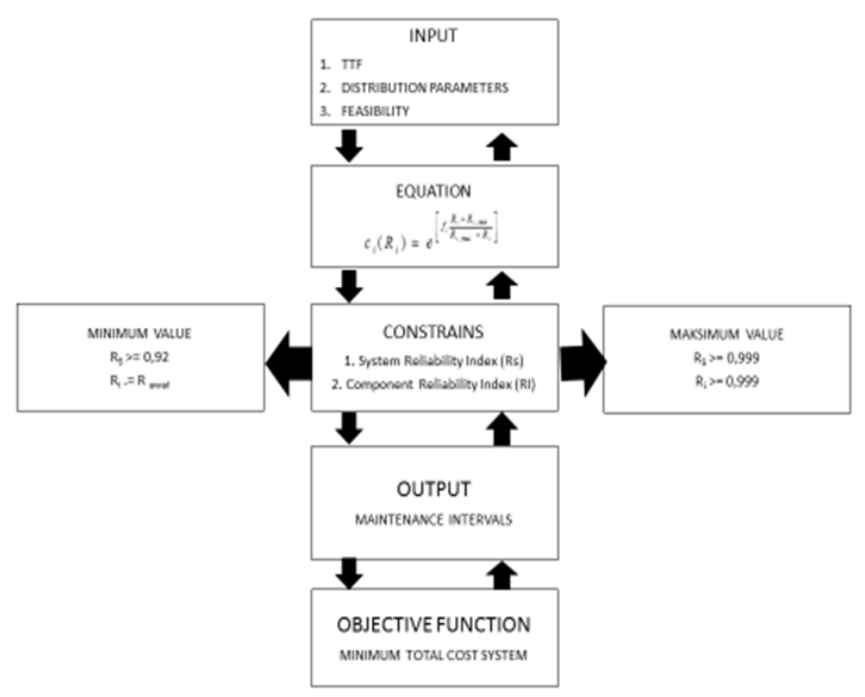

Fig. 4 Reliability optimization modeling structure

\subsection{Data Analysis}

\subsubsection{Condition of the Cannon Before Optimization}

The calculation of system conditions is based on data obtained from the failure of each component that occurs within the operational time period of 2190 hours with a total of 8 damage times so that the average usage time is 273.5 hours of operation. Thus the calculation results can be obtained as follows:

Table 1. Conditions of Bofors cannons not $120 \mathrm{~mm} /$ $46 \mathrm{~A}$ before optimization

\begin{tabular}{|l|r|l|l|l|}
\hline Komponen & $\mathrm{R}(\mathrm{t})$ & $\mathrm{F}(\mathrm{t})$ & M(t) & MTTF \\
\hline aving unit & 0.5089 & 0.4911 & 0.01031 & 111.7192 \\
\hline ampifier & 0.8174 & 0.1828 & 0.00381 & 203.5100 \\
\hline Hydraulic gear & 0.6713 & 0.3287 & 0.00607 & 181.3291 \\
\hline Motor laving & 0.8558 & 0.1442 & 0.00255 & 285.2859 \\
\hline Force motor & 0.8192 & 0.1808 & 0.00389 & 447.6887 \\
\hline Rate Gyo & 0.8332 & 0.1688 & 0.00345 & 227.9230 \\
\hline Sistem & 0.1631 & 0.8389 & 0.02988 & \\
\hline
\end{tabular}

\subsubsection{Data Processing Results with the Solver Program}

In carrying out the optimization process to improve the reliability index, the author uses the help of the Premium Solver Program (PSP) software from Microsoft Excel. This optimization process aims to obtain a minimum sub-system reliability index of 0.92 with a total cost of increasing the minimum reliability index.

Table 2. Results of Optimization with the Solver Program

\begin{tabular}{|c|c|c|c|c|}
\hline Komponen & Feasloll:y & $\begin{array}{c}\text { baya } \\
\text { komponen }\end{array}$ & $\begin{array}{c}\text { Interval } \\
\text { perawatan }\end{array}$ & $\mathrm{R}(\mathrm{t})$ \\
\hline Laylng Un? & 0.3 & 37.8616 & 46 & 0.96096 \\
\hline A moller & 0.1 & 122079 & 84 & 0.99074 \\
\hline -ydraullo Gear & 0.1 & 14.1846 & 76 & 0.99004 \\
\hline Fone Motor & 0.1 & 8.4235 & 69 & 0.99423 \\
\hline Notor Laylng & 0.1 & 15.4836 & 68 & 0.96926 \\
\hline Fate Guro & 0.1 & 10.6403 & 60 & 0.99246 \\
\hline Total & & 98.8015 & & 092008 \\
\hline
\end{tabular}

\subsubsection{Condition of Cannon After}

\section{Optimization}

The condition of the cannon after reliability optimization is an increase in the reliability index as in table 3 below: 
Table 3. Cannon Conditions after optimization

\begin{tabular}{|c|c|c|c|c|}
\hline Komponen & $R(t)$ & $F(t)$ & $\lambda(t)$ & MTTF \\
\hline laying unit & 0.96096 & 0.039 & 0.0014 & 258258 \\
\hline amplifier & 0.99074 & 0.0093 & 0.0003 & 408.985 \\
\hline Hydraulic gear & 0.99004 & 0.0100 & 0.0003 & 412.969 \\
\hline Motor laving & 0.98928 & 0.0107 & 0.0004 & 570910 \\
\hline Force motor & 0.99423 & 0.0058 & 0.0002 & 881.081 \\
\hline Rate Gyo & 0.99248 & 0.0075 & 0.0003 & 881.158 \\
\hline Sisten & 0.92008 & 0.0799 & & \\
\hline
\end{tabular}

\section{CONCLUSION.}

From the results of reliability optimization calculation, it can be seen that the greater the percentage increase in the reliability index of a component, the greater the cost required. In maintenance activities to improve the reliability of a system cannot be implemented only on critical components. The greater the increase in the reliability index, the greater the costs required.

\section{BIBLIOGRAPHY.}

Defense, D.o. (1980) Military Handbook 1629A, Procedure for Performing A Failure Modes, Effect and Criticality Analysis., USA.

Defense, D.o. (1998) Department of Defense USA (1980), Military Handbook 338B, Electronic Realiability Design Handbook, USA.

Geuna, F., Weber, P. and Theulliol, D. (2011) 'Design of a fault tolerant control system incorporating reliability analysis and dynamic behaviour constraints', International Journal of Systems Science, no. Vol 42.
Han, T.S. (2000) 'The Reliability functions of the general souce with fixed-length coding', IEEE Transactions on Information Theory, no. IEEE Press Piscatway, NJ, USA, pp. 2117-2132.

Hartanto, E.T. (2016) 'aplikasi Failure Mode Effect And Criticality Analysis (Fmeca) Dalam Penentuan Interval Waktu Penggantian Komponen Kritis Radar Jrc Jma 5310 Pada Kri Satuan Kapal Patroli Koarmatim', Analisa Sistem \& Riset Operasi, no. Vol 6.

Jardine, A. (1973) Maintenace, Replacement and Realibility, Birmingham: Pitman Pulishing.

Kececioglo, D. (2002) Reliability Engineering Handbook, $1^{\text {st }}$ edition, Arizona: Dept Aerospace and Mechanical Engineering, Univercity of Arizona.

McCool, J. (2012) Using the Weibull Distribution : Reliability, Modeling and Inference, New Jersey: Jhon Wiley \& Sons Inc.

Moubray, J. (1997) Reliability-Centered Maintenace, New York: Industrial Press Inc. 